OPEN ACCESS

Edited by:

Li Shuai,

Fujian Agriculture and Forestry

University, China

Reviewed by:

Yanding Li,

Massachusetts Institute of Technology, United States

Somnath D. Shinde,

Sandia National Laboratories (SNL),

United States

${ }^{*}$ Correspondence: Jia-Long Wen

wenjialonghello@126.com; wenjialong@bjfu.edu.cn

Specialty section:

This article was submitted to

Bioenergy and Biofuels,

a section of the journal

Frontiers in Energy Research

Received: 10 May 2020

Accepted: 09 July 2020

Published: 18 September 2020

Citation:

Zhang C, Xu L-H, Ma C-Y, Wang $H-M$, Zhao $Y-Y$, Wu $Y-Y$ and

Wen J-L (2020) Understanding

the Structural Changes of Lignin Macromolecules From Balsa Wood

at Different Growth Stages.

Front. Energy Res. 8:181. doi: 10.3389/fenrg.2020.00181

\section{Understanding the Structural Changes of Lignin Macromolecules From Balsa Wood at Different Growth Stages}

\author{
Chen Zhang ${ }^{1}$, Ling-Hua Xu ${ }^{1}$, Cheng-Ye Ma ${ }^{1}$, Han-Min Wang ${ }^{1}$, Yuan-Yuan Zhao ${ }^{2}$, \\ Yu-Ying $W u^{1}$ and Jia-Long Wen ${ }^{1,2 *}$ \\ 'Beijing Key Laboratory of Lignocellulosic Chemistry, Beijing Forestry University, Beijing, China, ${ }^{2}$ Beijing Advanced \\ Innovation Center for Tree Breeding by Molecular Design, Beijing Forestry University, Beijing, China
}

Lignin is the most abundant aromatic biomacromolecule on the earth, which is an attractive raw material for producing bio-based chemicals, materials, and fuels. However, the complexity, heterogeneity, and variability of the lignin structure always hinders the value-added application of different sources of raw materials. In this study, double enzymatic lignin (DEL) was isolated from balsa grown for different lengths of time to understand the structural variations of lignin macromolecules during the growth of balsa for the first time. Confocal Raman microscopy and component analysis were used to monitor the lignin accumulation in balsa. Meanwhile, the structural characteristics and chemical reactivity of DELs were synthetically characterized by advanced 2D-HSQC and ${ }^{31} \mathrm{P}-\mathrm{NMR}$ techniques. It was found that the balsa lignin is a typical hardwood lignin and it is overwhelmingly composed of $\mathrm{C}-\mathrm{O}$ bonds (i.e., $\beta-\mathrm{O}-4$ linkages), whose content is elevated with increasing tree-age. Interestingly, carbon-carbon linkages (e.g., $\beta-\beta$ and $\beta-5)$ in these DELs isolated from 3-and 5-year-old balsa are gradually disappearing. Considering the increasing molecular weight of DELs with tree-age, it was concluded that lignin macromolecules in balsa wood were gradually polymerized within the growth period. Furthermore, abundant $\mathrm{C}-\mathrm{O}$ linkages with less $\mathrm{C}-\mathrm{C}$ linkages in the DELs from 3 and 5-year-old balsa wood suggested that these feedstocks are promising in current lignin-first biorefinery and will facilitate the conversion of aromatic chemicals from the lignin macromolecule. In short, a comprehensive understanding of native lignin during the growth of balsa wood will not only advance the understanding of biosynthetic pathways of lignin biopolymer, but also facilitate the deconstruction and value-added applications of this kind of feedstock.

Keywords: balsa wood, lignin macromolecules, structural characterization, native lignin, 2D-HSQC NMR

\section{INTRODUCTION}

Lignin is the most abundant natural biopolymer in the plant cell wall of the lignocellulosic biomass. Structurally, it is a heterogeneous and aromatic macromolecule polymer, which is mainly comprised of three kinds of component units, syringyl (S) units, guaiacyl (G) units, and $p$-hydroxyphenyl $(\mathrm{H})$ units by biosynthesizing under the regulation of different kinds of enzymes 
(Ralph et al., 2004; Rinaldi et al., 2016; Baruah et al., 2018). These units are linked by ether (e.g., $\beta-O-4)$ and carbon-carbon $(\beta-5, \beta-\beta$, etc.) bonds via free radical coupling reactions (Ralph and Landucci, 2010). Besides these lignin substructures, lignin and hemicelluloses are also linked by ether and ester bonds, forming the common lignin-carbohydrate complexes (LCC), such as phenyl glycoside, benzyl ether, and $\gamma$-ester (Balakshin et al., 2011; Yuan et al., 2011; Huang et al., 2018). However, the native structure of lignin varies with tree species (Wang et al., 2017), growth stages (Wang et al., 2020), different cell wall tissues (Wen et al., 2013a), leading to challenges in the utilization of lignocellulosic feedstocks. Therefore, detailed investigation of microscopic distribution of lignin in cell wall and molecular structures of lignin in the lignocellulosic biomass will facilitate deconstruction and value-added applications of the plant cell walls in the current biorefinery (Ragauskas and Yoo, 2018).

Balsa wood (Ochroma pyramidale) grows in tropical forests of the Americas, and is the lightest and fastest-growing tree in the world (O'Dowd, 1979). The diameter of the balsa wood trunk changes quite dramatically as it grows (Supplementary Figure S1). Balsa wood was introduced into southern China in the 1950s and 1960s (Shu, 1998), and it has also been planted on a large scale in Fujian, Yunnan, Guangdong, and southern districts in China. Balsa wood is currently used in the production of aero models, adsorption materials, and heat insulation materials (Fu et al., 2017; Guan et al., 2018). Lignin plays an important role in plant growth. Due to its fast growth rate and high wood yield during the balsa growing process, understanding the lignin accumulation and structural variations of lignin macromolecules in the balsa plant cell wall is of great importance. From the perspective of the utilization of lignocellulose, the presence of lignin in the plant cell wall is deemed to be a major biomass recalcitrance (Yuan et al., 2013; Huang et al., 2019). Thus, lignin is generally removed in the preliminary steps of biorefinery (Ding et al., 2012; Zeng et al., 2014). Moreover, during the different processing methods for balsa wood, a lot of processing leftovers were produced. Therefore, understanding the chemical composition and structural features of native lignin in balsa wood will facilitate the deconstruction of the compact cell wall and value-added applications of the fractionated components (lignin, hemicelluloses, and cellulose) in the current biorefinery.

Based on the above considerations, it is necessary to illustrate the structural features of native lignin. The basic knowledge available for isolation methods (MWL, CEL, EMAL, and their improved form) of native lignin were reported by some pioneers (Björkman, 1954; Chang et al., 1975; Wu and Argyropoulos, 2003; Zhang et al., 2010). Recently, a native lignin named double enzymatic lignin (DEL) was developed for isolating native lignin from different biomasses due to the ideal yields and unaltered structures (Chen et al., 2017; Wang et al., 2017, 2020). In the present study, balsa wood with different growth years $(1,3$, and 5 years) were used to reveal structural changes of lignin macromolecules. Herein, DEL samples were isolated from the different growth stages of wood for the first time, NMR and GPC techniques were performed to investigate the structural changes of lignin during the different growth stages. Furthermore, Raman microscopy was performed to investigate the lignin distribution in the cell walls of balsa wood.

\section{MATERIALS AND METHODS}

\section{Materials}

The balsa wood was prepared from 1-, 3-, and 5-year-old trees, harvested from one Forestry Center in Fujian Province, China. The raw materials were harvested in summer and then underwent air-drying. The air-dried wood was smashed into powder (2060 mesh), dried in an oven at $60^{\circ} \mathrm{C}$ for $24 \mathrm{~h}$, then extracted in a Soxhlet extractor for $6 \mathrm{~h}$ with ethanol/benzene $(1: 2, \mathrm{v} / \mathrm{v})$. The chemical compositions of the different balsa woods were analyzed according to the method from the National Renewable Energy Laboratory (NREL; Sluiter et al., 2008). To isolate the native lignin DEL, the pre-extracted balsa woods were airdried and then milled in the planetary ball mill (450 rpm, $5 \mathrm{~h}$ ) to obtain the ball-milled powder (Wang et al., 2020). The chemicals were purchased from Sigma-Aldrich (Shanghai), and the commercial cellulase (Cellic CTec2, $100 \mathrm{FPU} / \mathrm{mL}$ ) was provided by Novozymes (Beijing, China).

\section{Preparation of DELs From Different Growth Stages of Balsa Wood}

The isolation of DEL was performed according to our previous publications (Chen et al., 2017; Wang et al., 2020). In detail, ballmilled balsa wood $(1,3$, and 5 years) powders were subjected to enzymatic hydrolysis in the acetate buffer $(0.05 \mathrm{~mol} / \mathrm{L}, 200 \mathrm{~mL}$, $\mathrm{pH} 4.8$ ), then cellulase (50 FPU/g) was added. The reaction mixtures were incubated in a rotary shaker $\left(50^{\circ} \mathrm{C}, 150 \mathrm{rpm}\right)$ for $48 \mathrm{~h}$. The enzymatic residues were washed repeatedly with hot water to remove the hydrolyzed carbohydrates, centrifuged, and freeze-dried. The obtained solids underwent ball-milling for $2 \mathrm{~h}$ and then underwent the same enzymatic hydrolysis. After the purification and freeze-drying process, the DEL samples were achieved, labeled as DEL-1, DEL-3, and DEL-5.

\section{Characterizations of Lignin}

The characterizations of the lignin were described in detail in the Supplementary Material section.

\section{RESULTS AND DISCUSSION}

\section{Chemical Composition of Balsa Wood During Different Growth Stages}

Biomass characterization of balsa wood is crucial to understand the component changes of balsa wood during growth stages. The characterization of lignin not only enhance the understanding of structural changes during the growth process of balsa wood, but also facilitate the subsequent dissociation, utilization, and conversion of balsa components into chemicals, energy, and biomaterials in the current biorefinery scenario. The chemical compositions of balsa wood with different growth stages (1,3, and 5 year) are displayed in Table 1 . As shown, the content of cellulose 
TABLE 1 | Chemical composition of different growth years of balsa wood (w/w, \%).

\begin{tabular}{|c|c|c|c|c|c|c|}
\hline Materials & Cellulose & Hemicelluloses $^{a}$ & $\mathbf{K L}^{\mathbf{b}}$ & $\mathrm{ASL}^{\mathrm{c}}$ & $T^{d}{ }^{d}$ & Total \\
\hline 1 & $45.04 \pm 0.9$ & $16.93 \pm 0.3$ & $18.03 \pm 0.5$ & $4.04 \pm 0.1$ & 22.07 & 84.04 \\
\hline 3 & $44.57 \pm 1.2$ & $17.15 \pm 0.2$ & $19.67 \pm 0.4$ & $5.25 \pm 0.1$ & 24.92 & 86.64 \\
\hline 5 & $42.03 \pm 1.0$ & $18.02 \pm 0.2$ & $18.60 \pm 0.5$ & $5.45 \pm 0.1$ & 24.05 & 84.10 \\
\hline
\end{tabular}

a Hemicelluloses are composed of xylose, mannose and uronic acid. ${ }^{b}$ Klason lignin. ${ }^{c}$ Acid soluble lignin. ${ }^{d}$ Total lignin.

in balsa wood decreased from 45.0 to $42.0 \%$ as the growth years increased. This is in disagreement with other hardwood species, such as poplar wood, at early growth stages (3-18 months) (Wang et al., 2020). However, the relatively high contents of cellulose in balsa woods at different growth stages suggested that balsa woods are more likely to release more cellulose for cellulose-based materials and fermentable glucose production. By contrast, the content of hemicelluloses in balsa wood was slightly elevated with increased tree-age. Correspondingly, the lignin content was first increased from $22.1 \%$ for 1 -year-old to $25.0 \%$ for 3-year-old balsa wood, then the lignin content in 5-year-old balsa wood was slightly decreased to $24.1 \%$. This revealed that the accumulation of lignin increased with the growth of balsa wood and eventually stabilized in the mature period. In short, investigating the chemical composition of balsa wood and the detailed structural features of lignin macromolecules from balsa wood will facilitate the subsequent fractionation and conversion of the main components.

\section{Confocal Raman Microscopy Characterization of Lignin and Carbohydrate Distribution}

Confocal Raman Microscopy (CRM) is a useful tool that can provide an intuitionistic observation of lignin and carbohydrates in cell walls with a high resolution (Chen et al., 2017). The spatial dynamic distribution of lignin and carbohydrates in the cell walls from different growth stages of balsa woods can be monitored by CRM. Different concentrations of lignin in corner middle lamella (CCML), compound middle lamella (CML), and secondary (S) can be reflected by different intensities in CRM (Agarwal, 2006; Li et al., 2015). Raman images of lignin and carbohydrate distribution in the plant cell wall from balsa wood (different tree-age) are shown in Figure 1. Obviously, it was found that distributing concentrations of lignin and carbohydrates in different regions were quite different. The richest lignin was observed in CCML, followed by CML, and the lowest concentration of lignin was found in SW. This distribution patterns are verified in the different growth stages of balsa wood. In addition, it was observed that the relative concentration of lignin in the CCML, CML, and SW regions become higher from 1 to 3 years and slightly reduced in 5-year-old balsa wood, which was in line with the content of lignin in different growth stages of balsa wood (Table 1). In fact, the increased concentration of lignin in the CCML and CML regions of cell walls implied that lignin macromolecules can serve as a natural adhesive to further support plant cell walls during balsa growth. Contrary to the distribution of lignin in the cell wall, carbohydrate distribution was abundant in the SW layer, while carbohydrate concentration was lowest in CCML regions. Furthermore, it was observed from CRM images that the cell wall thickness obviously increases with the growth stages of balsa wood.

\section{Yields and Associated Carbohydrates of Lignin Fractions}

Prior to structural characterization of native lignin in plant cell walls, it is hoped that the yield of isolated native lignin would be high enough so that the characterization of lignin could truly reveal the lignin composition and structural features in the cell wall. In the current study, the structural variations of lignin from different growth years of balsa wood can be achieved via isolation and characterization of DEL. From Table 2, it was found that the crude yields of the three DEL samples are more than $100 \%$ (from 102.6 to $105.4 \%$ ). It should be noted that the content of associated carbohydrates in these DELs is from 5.84 to $8.02 \%$ (based on the total weight of lignin). Among the associated carbohydrates, xylose and glucose are the dominant sugars. The phenomenon is easy to explain because DEL is a residual lignin after removing xylans and cellulose by the enzymatic hydrolysis process. However, as the main components in a plant cell wall, hemicelluloses (xylans) and cellulose could not be totally removed. Meanwhile, a small amount of galactose also contributed to the total associated carbohydrates in these DEL samples. After eliminating the effect of carbohydrates on yield, the yield of lignin without carbohydrates is from 96.7 to $98.0 \%$. In short, DEL with a high yield is a better representation of the entire lignin in the plant cell walls and can reveal the structural changes of native lignin from balsa wood with different tree-age.

\section{Molecular Weights Analysis of DELs}

In order to improve the solubility of DEL in tetrahydrofuran for GPC determination, acetylation of DEL was performed as previously reported (Wang et al., 2017). The molecular weights $\left(M_{w}\right.$ and $\left.M_{n}\right)$ and polydispersity index (PDI, $M_{w} / M_{n}$ ) of acetylated DEL samples are shown in Table 3, which were calculated from the GPC curves (relative values related to polystyrene). GPC results showed that $M w$ of DEL gradually elevated from $8460 \mathrm{~g} / \mathrm{mol}$ (1-year-old balsa) to $8800 \mathrm{~g} / \mathrm{mol}$ (3year-old balsa) and then further climbed to $10,050 \mathrm{~g} / \mathrm{mol}$ (5-yearold balsa). These results suggested that polymerization degrees of lignin macromolecules increase gradually as balsa wood grows. The increased trend has also been observed in our recent study (Wang et al., 2020). Meanwhile, the PDI (about 1.5) is less than those (1.8-2.0) of DELs from poplar wood (Wang et al., 2020). This implied that the lignin macromolecules from balsa are more homogeneous, which is beneficial to the utilization of this kind of lignin. In fact, the homogeneous lignin is mostly related to 

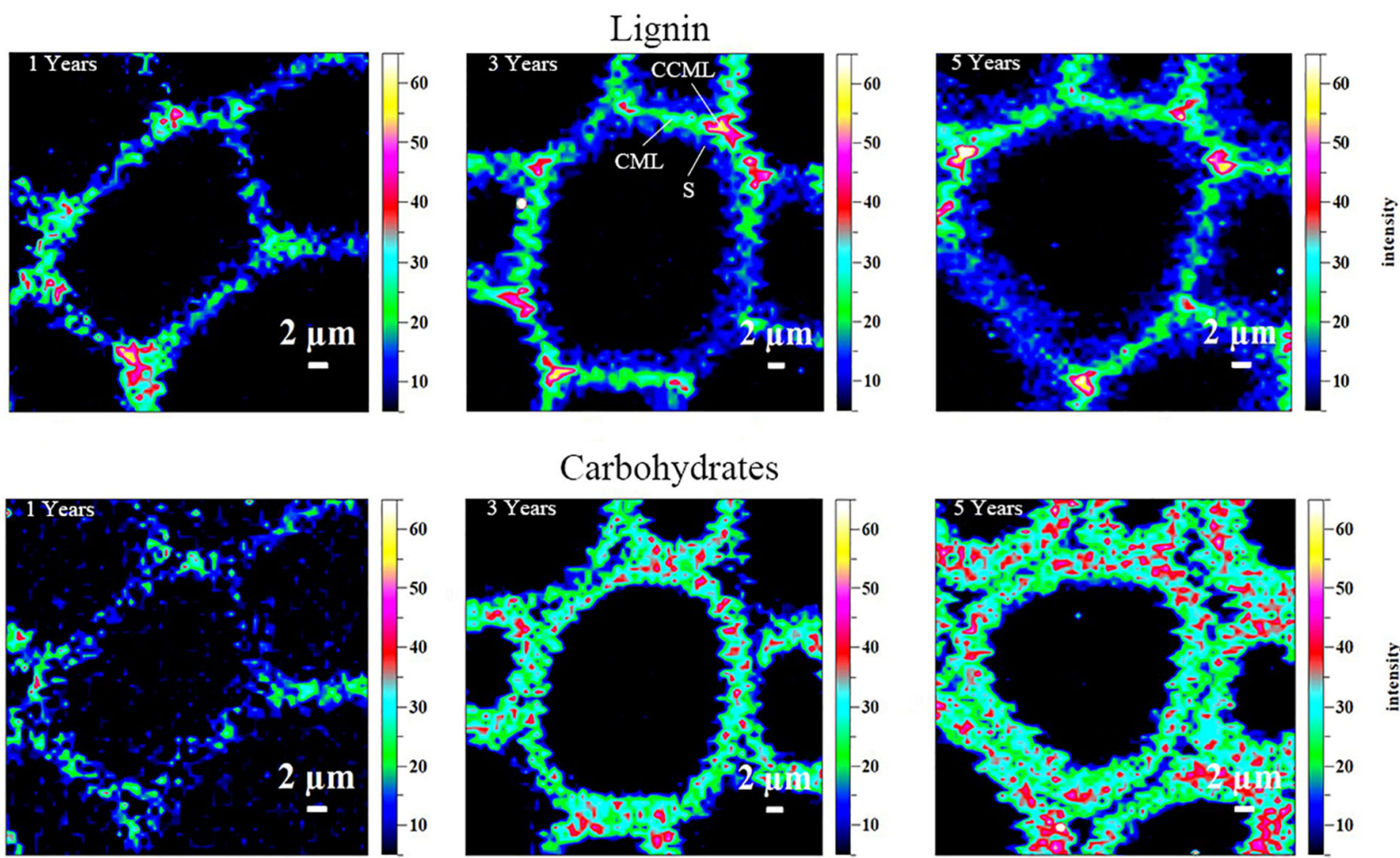

FIGURE 1 | Raman images of the lignin (by integrating from 1547 to $1707 \mathrm{~cm}^{-1}$ ) and carbohydrates (by integrating the band at $2889 \mathrm{~cm}^{-1}$ ) distributions in the different growth years of balsa wood cell walls.

TABLE 2 | Yields and carbohydrate content of lignin fractions.

\begin{tabular}{lccccc}
\hline Samples & Yield (\%) & Total carbohydrates (\%) & Yield (\%) & & \multicolumn{2}{c}{ Carbohydrates content (\%) } \\
\cline { 4 - 6 } & & & & Gal $^{\mathbf{c}}$ & Glu $^{\mathbf{c}}$ \\
\hline DEL-1 & 103.7 & 5.84 & 98.0 & 0.56 & 2.84 \\
DEL-3 & 102.6 & 6.10 & 96.7 & 0.52 & 3.22 \\
DEL-5 & 105.4 & 8.02 & 97.6 & 0.60 & 3.67 \\
\hline
\end{tabular}

${ }^{a}$ The yield of lignin was calculated based on the Klason lignin of different balsa wood (with carbohydrates). ${ }^{b}$ The yield of lignin was calculated based on the Klason lignin of different balsa wood (without carbohydrates). ' Gal, galactose; Glu, glucose; Xyl, xylose.

TABLE 3 | Weight-average molecular weights $\left(M_{W}\right)$ and number-average molecular weights $\left(M_{n}\right)$, and polydispersity $\left(M_{w} / M_{n}\right)$ of the lignin fractions.

\begin{tabular}{lccc}
\hline Samples & $\mathbf{M}_{\mathbf{w}}$ & $\mathbf{M}_{\mathbf{n}}$ & $\mathbf{M}_{\mathbf{w}} / \mathbf{M}_{\mathbf{n}}$ \\
\hline DEL-1 & $8460 \pm 40$ & $5740 \pm 60$ & 1.47 \\
DEL-3 & $8800 \pm 60$ & $5790 \pm 70$ & 1.52 \\
DEL-5 & $10050 \pm 90$ & $6710 \pm 50$ & 1.50 \\
\hline
\end{tabular}

the inherent structure of lignin, which will be verified in the subsequent NMR section.

\section{D-HSQC Spectra of DELs}

To obtain the chemical composition and detailed structural characteristics of native lignin from balsa wood, the DEL samples were characterized by the 2D-HSQC NMR and the spectra were analyzed according to previous publications regarding the 2DHSQC characterizations of different lignin sources (Kim and Ralph, 2010; del Río et al., 2012; Wen et al., 2013b). In addition, the recent advances in characterization of lignin polymer by solution-state NMR (especially 2D-HSQC spectra) have been reviewed in detail in our previous publication (Wen et al., 2013b). The side-chain and aromatic regions in 2D-HSQC NMR spectra of the DELs as well as the main identified substructures are depicted in Figure 2. It was found that the 2D-HSQC NMR spectra of lignin from balsa wood are analogical to those from other hardwood species, such as eucalyptus wood (Wang et al., 2017). However, the DELs from different growth stages of balsa wood presented impressive spectral characteristics. Based on these NMR spectra, it was found that the native lignin samples from balsa wood under different tree-ages exhibited gradually changing structural features, which is also the important basis for subsequent utilizations of balsa wood. 


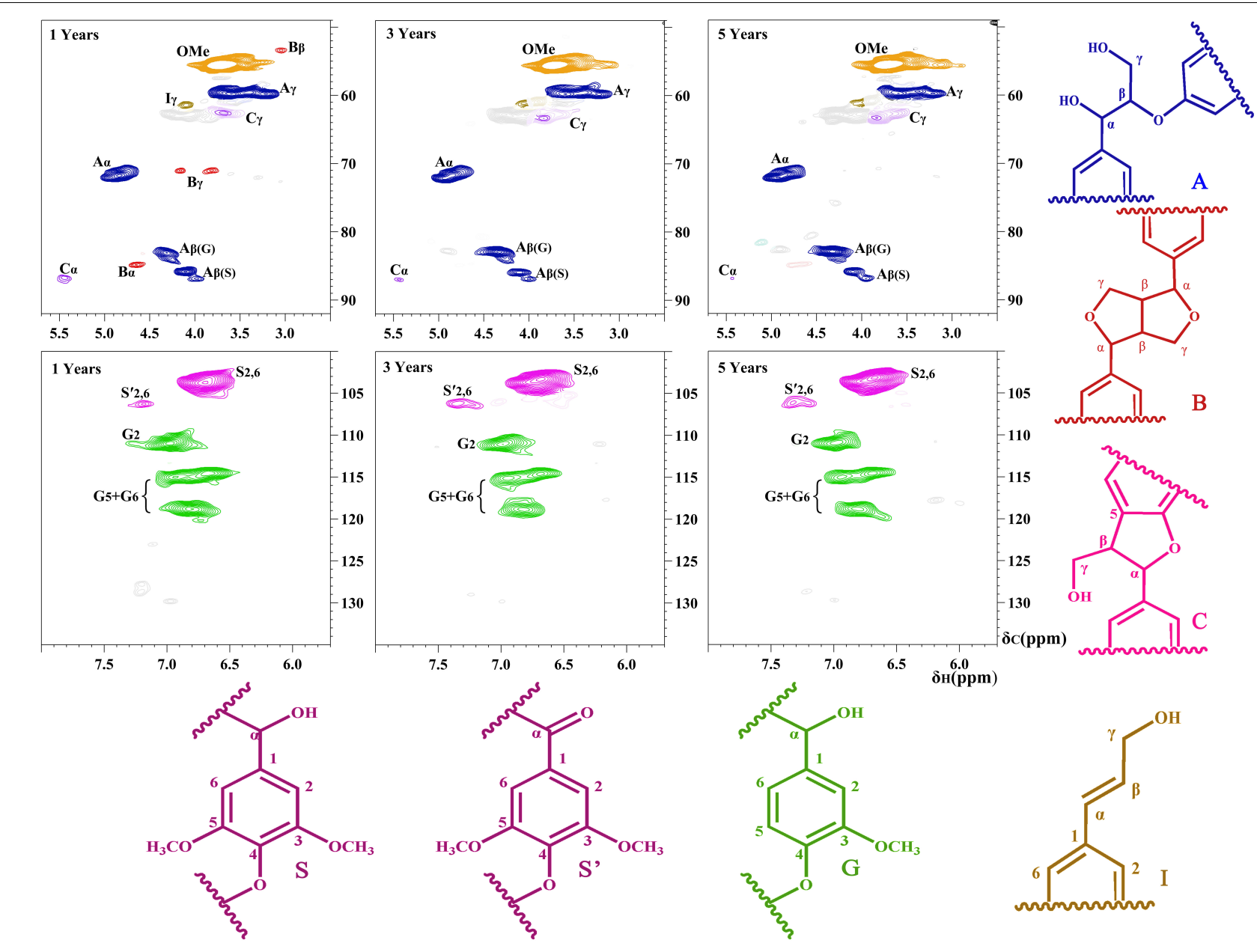

FIGURE 2 | Side-chain and aromatic regions in the 2D-HSQC NMR spectra of the DELs isolated from balsa wood.

In general, the side-chain regions in the 2D-HSQC spectra provided useful information on the substructures in the lignin macromolecules. In this study, it was found that the structural characteristics of different DEL samples exhibited distinct spectra, suggesting that native lignin in different growth years of balsa wood are fundamentally different. These different lignin structures also laid a foundation for the oriented pretreatment and processing of balsa wood. Regarding to the spectral assignments, it should be noted that all the spectra presented the prominent signal corresponding to $\beta-O-4$ aryl ethers (A). However, the carbon-carbon (C-C) substructures (e.g., $\beta-\beta$ and $\beta-5$ ), which are very common in most wood species, only partly appeared in native lignin from the 1-year-old balsa wood. By contrast, the DEL samples from 3-year and 5-year-old balsa wood are predominantly composed of $\beta-O-4$ aryl ethers (A), only a minor amount of $\beta$-5 linkages and $p$-hydroxycinnamyl alcohol end group (I) substructures were detected in these DEL samples. In fact, the native lignin with abundant $\mathrm{C}-\mathrm{O}$ bonds $(\beta$ $O-4$ linkages) and less carbon-carbon $(\mathrm{C}-\mathrm{C})$ bonds $(\beta-\beta, \beta-5$, and $\beta-1)$ is a promising feedstock for the current biorefinery process. As we known, some transgenic poplar wood (up-regulation of
$\mathrm{F} 5 \mathrm{H}$ in poplar wood) also achieves this purpose and obtains the native lignin with high $\mathrm{C}-\mathrm{O}$ and less $\mathrm{C}-\mathrm{C}$ bonds (Rinaldi et al., 2016; Shuai et al., 2016), however, the transgenic technology is high-cost and there is still instability in the cultivation of forest resources at present. Thus, the utilization cost of large amounts of naturally occurring biomass resources would be significantly reduced and availability would be much higher. Additionally, protective lignin extraction strategies were successfully proposed to protect the $\mathrm{C}-\mathrm{O}$ linkages and simultaneously suppress the formation of $\mathrm{C}-\mathrm{C}$ linkages, which is beneficial to subsequent production of lignin monomers with high-yield via catalytic hydrogenolysis (Luterbacher et al., 2015; Shuai et al., 2016; Lan et al., 2018). Therefore, it can be concluded that 3- and 5-yearold balsa wood has great potential for the subsequent lignin-first biorefinery scenario.

In the aromatic region, syringyl (S) and guaiacyl (G) were clearly presented. In more detail, the $S$ units showed a visible signal for the $S_{2,6}$ correlations, and the minor signal for the $\mathrm{C} \alpha$-oxidized S-units ( $\left.\mathrm{S}^{\prime}\right)$ also appeared. Besides, there are three distinct cross-signals of $\mathrm{G}$ units: $\mathrm{C} 2-\mathrm{H} 2, \mathrm{C} 5-\mathrm{H} 5$, and C6-H6. For the aromatic region of the spectra, there seems to be no obvious 
TABLE 4 | Quantification of lignin fractions by quantitative 2D-HSQC NMR method.

\begin{tabular}{lcccc}
\hline Samples & $\boldsymbol{\beta - O - 4}$ & $\boldsymbol{\beta}-\boldsymbol{\beta}$ & $\boldsymbol{\beta}-\mathbf{5}$ & $\mathbf{S} / \mathbf{G}^{\mathbf{a}}$ \\
\hline DEL-1 & $66.33^{\mathrm{b}}(84.92 \%)^{\mathrm{c}}$ & $5.31(6.80 \%)$ & $6.47(8.28 \%)$ & 1.25 \\
DEL-3 & $66.76(98.19 \%)$ & $\operatorname{Tr}^{\mathrm{d}}$ & $1.23(1.81 \%)$ & 2.49 \\
DEL-5 & $68.81(99.29 \%)$ & $\operatorname{Tr}$ & $0.49(0.71 \%)$ & 2.95 \\
\hline
\end{tabular}

a $S / G$ ratio obtained by this equation: $S / G$ ratio $=0.5 /\left(S_{2}, 6\right) / /\left(G_{2}\right)$. ${ }^{b}$ Results expressed per $100 \mathrm{Ar}$ based on quantitative 2D-HSQC spectra. ${ }^{C}$ Relative abundance of linkages (\% of total side chains involved). ${ }^{d} T r$, trace.

difference between these DEL samples. However, quantification of characteristic correlated signals in different DELs can provide detailed information regarding the chemical composition and relative content of different linkages (Wen et al., 2013b). As we all known, understanding the S/G ratio of DEL will not only help to reveal the rule of lignin accumulation and deposition in plant cell walls, but will also facilitate the subsequent delignification and deconstruction of this kind of feedstock (Rinaldi et al., 2016; Akinosho et al., 2017).

In the present study, it was observed that the $S / G$ ratio of $D E L$ from different growth stages (1,3, and 5-year-old) of balsa wood is $1.25,2.49$, and 2.95 , respectively. These continuously increasing $\mathrm{S} / \mathrm{G}$ ratios suggested that S-type lignin is naturally synthesized in the late stage of the plant cell wall formation of balsa wood. In addition, the existence of $S$ units preferentially promoted the formation of $\beta-O-4$ linkage in a hardwood biomass (Ralph and Landucci, 2010). This prediction was also demonstrated in the present study since the abundance of $\beta-O-4$ linkages is positively related to the $S / G$ ratios of these lignin macromolecules (Table 4). For example, the abundance of $\beta-O-4$ linkages based on $100 \mathrm{Ar}$ in DEL-1, DEL-3, and DEL-5 was 66.33, 66.76, and 68.81/100Ar, respectively. Meanwhile, relative abundance of linkages based on total side chains also exhibited a similar trend, the relative abundance of $\beta-O-4$ linkages in DEL-1, DEL-3, and DEL-5 was $84.92,98.19$, and $99.29 \%$, respectively. Additionally, the gradually decreasing $\beta-5$ linkage is also related to the increased $\mathrm{S} / \mathrm{G}$ ratio because $\beta-5$ linkage is mainly synthesized by the $\mathrm{G}$ units during the biosynthesis of the lignin macromolecule (Ralph and Landucci, 2010). Similarly, researchers have developed a toolkit for simulating lignin biosynthesis in silico and they found that increasing S-content drastically increases $\beta-O-4$ content under slow monomer addition conditions (Orella et al., 2019). This phenomenon also appears to be similar to what has been observed with $\mathrm{F} 5 \mathrm{H}$ up-regulated lignin, in which the content of $\beta-O$ 4 content is positively related to the ratio of $S$ units in lignin
(Stewart et al., 2009). In general, the structural characteristics of lignin components obtained from a feedstock biomass and biorefinery processes have a direct effect on the outcomes in future conversion processes. According to previous studies (Rinaldi et al., 2016; Schutyser et al., 2018), the abundant $\beta-O-4$ linkages in these DEL samples are conducive to the downstream conversion of lignin into aromatic molecules. However, apart from $S / G$ ratios and $\beta-O-4$ abundance in lignin, the chemical reactivity (i.e., different functional groups) of the different lignin fractions is also the most important molecular feature that determines its availability in the conversion process of these lignin feedstocks (Wang et al., 2020).

\section{${ }^{31} \mathrm{P}-\mathrm{NMR}$ Analysis of DELs}

The ${ }^{31} \mathrm{P}$ NMR technique can accurately quantify the content of functional groups (such as $\mathrm{OH}$ and $\mathrm{COOH}$ groups) of lignin with the aid of the internal standard (Argyropoulos, 1995). The functional groups in these lignin fractions can be determined by the ${ }^{31} \mathrm{P}$ NMR technique (Supplementary Figure S2) and the results are shown in Table 5. Based on the obtained data, it was found that the detected amount of phenolic $\mathrm{OH}$ is less and the content of S-type phenolic $\mathrm{OH}$ is similar to that of G-type phenolic OH. This fact suggested that $\beta-O-4$ linkage in these lignin macromolecules were mainly composed of S-type and G-type lignin units, thus only less phenolic $\mathrm{OH}$ was determined by the ${ }^{31} \mathrm{P}$ NMR spectra. Additionally, the continuously decreasing contents of phenolic $\mathrm{OH}$ groups (S-type phenolic $\mathrm{OH}$, condensed G-type phenolic $\mathrm{OH}$, and non-condensed G-type phenolic $\mathrm{OH}$ ) from these lignin macromolecules were observed with the increasing age of the trees. This fact suggested that phenolic $\mathrm{OH}$ groups in DELs from 3 and 5-year-old balsa wood are occupied in the form of $\beta-O-4$ linkage and possible LCC bonds, such as phenyl glycoside bonds, which can be revealed by the high content of $\beta-O-4$ linkage and carbohydrates in DEL-3 and DEL-5. Therefore, deducting the possible effects of carbohydrates in lignin, the content of the phenolic $\mathrm{OH}$ group is inversely related to the amount of $\beta$-O4 linkage in the lignin extracted from same feedstock using the same method. In general, if a native lignin contains less content of S-type and G-type phenolic $\mathrm{OH}$ groups, the content of $\beta$ - $O$ 4 linkage is abundant. With regard to the $\mathrm{COOH}$ groups, it was found that the $\mathrm{COOH}$ in DEL-1 was higher than those from DEL-3 and DEL-5. Considering the difference of aliphatic $\mathrm{OH}$ and $\mathrm{COOH}$ groups in these lignin fractions, it should be realized that the amounts of aliphatic $\mathrm{OH}$ and $\mathrm{COOH}$ groups is not only

TABLE 5 | Quantification of lignin fractions by quantitative ${ }^{31} \mathrm{P}-\mathrm{NMR}$ method ( $\left.\mathrm{mmol} / \mathrm{g}\right)$.

\begin{tabular}{|c|c|c|c|c|c|}
\hline Samples & Aliphatic OH & S-type phenolic $\mathrm{OH}$ & \multicolumn{2}{|c|}{ G-type phenolic $\mathrm{OH}$} & Carboxylic Group \\
\hline DEL-3 & 3.60 & 0.33 & 0.05 & 0.29 & 0.07 \\
\hline DEL-5 & 2.85 & 0.27 & 0.05 & 0.23 & 0.08 \\
\hline
\end{tabular}

${ }^{a} \mathrm{C}$, condensed. ${ }^{b} \mathrm{NC}$, non-condensed. 


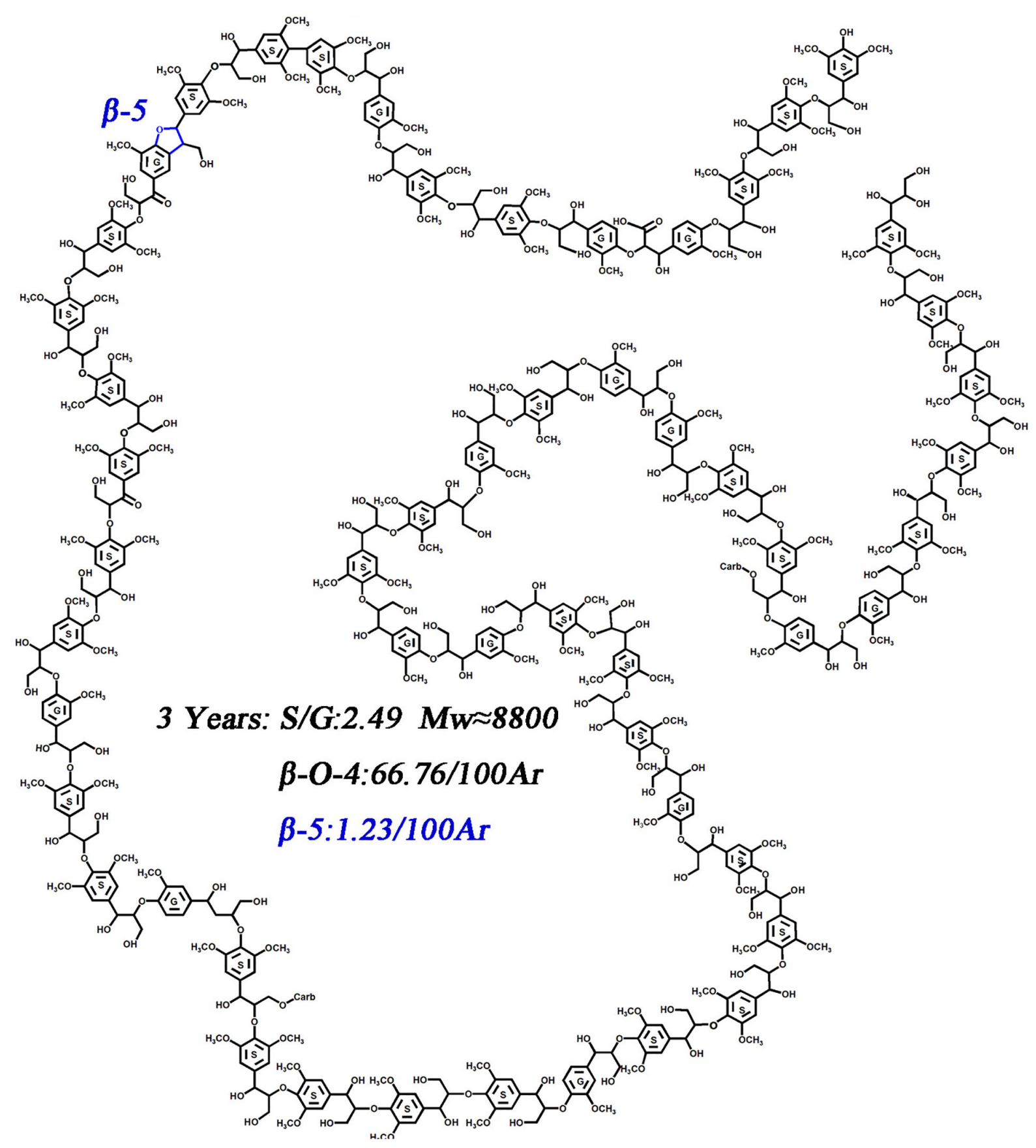

FIGURE 3 | Potential structural models of lignin macromolecules in 3-year-old balsa wood.

related to the different lignin substructures, but also affected by molecular weights of lignin.

\section{Possible Structural Models and Its Implications}

Lignin is generally separated and collected through different pretreatments and can be further developed into the renewable biomaterials or value-added chemicals, which depend on the structural characteristics of the raw material lignin (Schutyser et al., 2018). In the present study, the potential structural models (Figure 3 and Supplementary Figure S3) of native lignin macromolecules from different growing years of balsa feedstocks were proposed based on the structural characteristics of balsa lignin macromolecules such as molecular weights, C9 units, S/G ratios, and the relative contents of different interunit linkage. Although the structural models are not the authentic structures of native lignin, it can intuitively reflect the structural characteristics 
of the native lignin from balsa trees. In short, this kind of native lignin has abundant $\beta-O-4$ linkages and such linear structure, which is conducive to the current reductive catalytic fractionation (RCF) process (Renders et al., 2017, 2019). Alternatively, to better utilize this kind of feedstock and achieve biomass valorization, a pretreatment is needed to effectively isolate high-quality lignin from this kind of feedstock prior to carbohydrate conversion, which is beneficial to the subsequent lignin-oriented biorefinery. Based on the obtained lignin, the structural characteristics and chemical reactivity of the obtained lignin should be further analyzed prior to final conversion of the isolated lignin into value-added chemicals (lignin monomers) and materials (lignin-based polymers). If the ultimate purpose of this lignin is to produce aromatic chemicals (lignin monomers), the isolation/fractionation method therefore should meet the following requirements, (1) maximally retaining the native $\beta-O-4$ bonds in lignin; (2) decreasing the formation of carbon-carbon bonds; and (3) identifying the structural features of lignin during the pretreatment method. The chemical composition and structural features of the isolated lignin can be investigated by reliable and powerful 2D-HSQC methodology, which can provide qualitative and quantitative information on lignin structure (Wen et al., 2013b). If the final application of lignin focuses on the development of lignin-based polymers, isolated lignin fractions with abundant $\mathrm{OH}$ groups are desired because most chemical modifications rely on the amount of $\mathrm{OH}$ groups (Laurichesse and Avérous, 2014). The ${ }^{31} \mathrm{P}-\mathrm{NMR}$ technique is a powerful technique to quantify the amount of different hydroxyl groups in lignin, which will be beneficial to the chemical modification of isolated lignin in developing lignin-based materials. These advances in lignin structural analysis contribute to the subsequent value-added utilizations of lignin. In short, the above-mentioned structural information of native lignin from balsa wood will also bring new opportunities for current "ligninfirst" biorefinery.

\section{CONCLUSION}

In the present study, the representative native residual DELs from different growth years of balsa wood were first used to characterize the structural variations and evolution of balsa lignin during the growth process. At the micro level, the accumulation of lignin in the plant cell wall is reinforced in the 3- and 5-year-old balsa wood. NMR results showed that the DELs from different growth years of balsa trees have abundant $\beta-O-4$ linkages (66.33-68.81/100Ar) and increasing

\section{REFERENCES}

Agarwal, U. P. (2006). Raman imaging to investigate ultrastructure and composition of plant cell walls: distribution of lignin and cellulose in black spruce wood (Picea mariana). Planta 224, 1141-1153. doi: 10.1007/s00425-0060295-z

Akinosho, H. O., Yoo, C. G., Dumitrache, A., Natzke, J., Muchero, W., Brown, S. D., et al. (2017). Elucidating the structural changes to populus lignin during
S/G ratios (1.25-2.95). Remarkably, it was found that the lignin from 3- to 5-year-old balsa wood is overwhelmingly composed of $\beta-O-4$ linkages with fewer $\mathrm{C}-\mathrm{C}$ linkages, which is beneficial for the production of aromatic chemicals from lignin. Thus, the linear lignin having a high content of $\beta-O-$ 4 linkages in the lignin is essential to achieve a high-yield of aromatic monomers in the lignin catalytic hydrogenolysis process. Alternatively, this kind of feedstock with abundant $\beta-O-4$ linkages is promising for the current RCF process. In short, investigating the balsa lignin not only broadens the current understanding of structural changes of lignin during the growth process of the balsa tree, but also facilitates the downstream utilization of balsa lignin in the current "lignin-first" biorefinery process.

\section{DATA AVAILABILITY STATEMENT}

The original contributions presented in the study are included in the article/Supplementary Material, further inquiries can be directed to the corresponding author.

\section{AUTHOR CONTRIBUTIONS}

$\mathrm{CZ}$ and L-HX carried out the experiments and wrote the draft manuscript. C-YM and H-MW performed the data process and visualization. Y-YZ provided the balsa wood raw materials and conducted CRM analysis. Y-YW performed the composition analysis of the balsa wood. J-LW designed the experiment, checked the data, and revised and improved the manuscript. All authors discussed the results and read the manuscript.

\section{FUNDING}

This work was supported by the Beijing Forestry University Outstanding Young Talent Cultivation Project (2019JQ03006), National Natural Science Foundation of China (31872698), and National Key Research and Development Program of China (2019YFB1503801).

\section{SUPPLEMENTARY MATERIAL}

The Supplementary Material for this article can be found online at: https://www.frontiersin.org/articles/10.3389/fenrg. 2020.00181/full\#supplementary-material

consolidated bioprocessing with Clostridium thermocellum. ACS Sustain. Chem. Eng. 5, 7486-7491. doi: 10.1021/acssuschemeng.7b01203

Argyropoulos, D. (1995). 31 P NMR in wood chemistry: a review of recent progress. Res. Chem. Intermed. 21:373. doi: 10.1007/bf030 52265

Balakshin, M., Capanema, E., Gracz, H., Chang, H.-M., and Jameel, H. (2011). Quantification of lignin-carbohydrate linkages with high-resolution NMR spectroscopy. Planta 233, 1097-1110. doi: 10.1007/s00425-011-1359-2 
Baruah, J., Nath, B. K., Sharma, R., Kumar, S., Deka, R. C., Baruah, D. C., et al. (2018). Recent trends in the pretreatment of lignocellulosic biomass for value-added products. Front. Energy Res. 6:141. doi: 10.3389/fenrg.2018.00141

Björkman, A. (1954). Isolation of lignin from finely divided wood with neutral solvents. Nature 174, 1057-1058. doi: 10.1038/1741057a0

Chang, H.-M., Cowling, E. B., and Brown, W. (1975). Comparative studies on cellulolytic enzyme lignin and milled wood lignin of sweetgum and spruce. Holzforschung 29, 153-159. doi: 10.1515/hfsg.1975.29.5.153

Chen, T.-Y., Wang, B., Wu, Y.-Y., Wen, J.-L., Liu, C.-F., Yuan, T.-Q., et al. (2017). Structural variations of lignin macromolecule from different growth years of Triploid of Populus tomentosa Carr. Int. J. Biol. Macromol. 101, 747-757. doi: 10.1016/j.ijbiomac.2017.03.146

del Río, J. C., Rencoret, J., Prinsen, P., Martínez, ÁT., Ralph, J., and Gutiérrez, A. (2012). Structural Characterization of Wheat Straw Lignin as Revealed by Analytical Pyrolysis, 2D-NMR, and Reductive Cleavage Methods. J. Agricult. Food Chem. 60, 5922-5935. doi: 10.1021/jf301002n

Ding, S.-Y., Liu, Y.-S., Zeng, Y., Himmel, M. E., Baker, J. O., and Bayer, E. A. (2012). How does plant cell wall nanoscale architecture correlate with enzymatic digestibility? Science 338, 1055-1060. doi: 10.1126/science. 1227491

Fu, Q., Medina, L., Li, Y., Carosio, F., Hajian, A., and Berglund, L. A. (2017). Nanostructured wood hybrids for fire-retardancy prepared by clay impregnation into the cell wall. ACS Appl. Mater. Interfaces 9, 36154-36163. doi: $10.1021 /$ acsami.7b10008

Guan, H., Cheng, Z., and Wang, X. (2018). Highly compressible wood sponges with a spring-like lamellar structure as effective and reusable oil absorbents. ACS Nano 12, 10365-10373. doi: 10.1021/acsnano.8b05763

Huang, C.-X., Lin, W.-Q., Lai, C.-H., Li, X., Jin, Y.-C., and Yong, Q. (2019). Coupling the post-extraction process to remove residual lignin and alter the recalcitrant structures for improving the enzymatic digestibility of acidpretreated bamboo residues. Bioresour. Technol. 285:121355. doi: 10.1016/j. biortech.2019.121355

Huang, C.-X., Tang, S., Zhang, W.-Y., Tao, Y.-H., Lai, C.-H., Li, X., et al. (2018). Unveiling the structural properties of lignin-carbohydrate complexes in bamboo residues and its functionality as antioxidants and immunostimulants. ACS Sustain. Chem. Eng. 6, 12522-12531. doi: 10.1021/acssuschemeng. $8 \mathrm{~b} 03262$

Kim, H., and Ralph, J. (2010). Solution-state 2D NMR of ball-milled plant cell wall gels in DMSO-d(6)/pyridine-d(5). Org. Biomol. Chem. 8, 576-591. doi: $10.1039 / \mathrm{b} 916070 \mathrm{a}$

Lan, W., Amiri, M. T., Hunston, C. M., and Luterbacher, J. S. (2018). Protection Group Effects during $\alpha, \gamma$-Diol Lignin Stabilization Promote High-Selectivity Monomer Production. Angew. Chem. 57, 1356-1360. doi: 10.1002/anie. 201710838

Laurichesse, S., and Avérous, L. (2014). Chemical modification of lignins: towards biobased polymers. Progr. Polym. Sci. 39, 1266-1290. doi: 10.1016/j. progpolymsci.2013.11.004

Li, H.-Y., Sun, S.-N., Wang, C.-Z., and Sun, R.-C. (2015). Structural and dynamic changes of lignin in Eucalyptus cell walls during successive alkaline ethanol treatments. Indus. Crops Products 74, 200-208. doi: 10.1016/j.indcrop.2015.04. 048

Luterbacher, J. S., Azarpira, A., Motagamwala, A. H., Lu, F., Ralph, J., and Dumesic, J. A. (2015). Lignin monomer production integrated into the $\gamma$-valerolactone sugar platform. Energy Environ. Sci. 8, 2657-2663. doi: 10.1039.C5EE01322D

O'Dowd, D. J. (1979). Foliar nectar production and ant activity on a neotropical tree. Ochroma pyramidale. Oecologia 43, 233-248. doi: 10.1007/BF00344773

Orella, M. J., Gani, T. Z. H., Vermaas, J. V., Stone, M. L., Anderson, E. M., Beckham, G. T., et al. (2019). Lignin-KMC: a toolkit for simulating lignin biosynthesis. ACS Sustain. Chem. Eng. 7, 18313-18322. doi: 10.1021/acssuschemeng.9b03534

Ragauskas, A. J., and Yoo, C. G. (2018). Editorial: advancements in biomass recalcitrance: the use of lignin for the production of fuels and chemicals. Front. Energy Res. 6:118. doi: 10.3389/fenrg.2018.00118

Ralph, J., and Landucci, L. L. (2010). "NMR of lignins," in Lignin and Lignans: Advances in Chemistry, eds J. Schmidt, D. Dimmel, and C. Heitner (Boca Raton, FL: CRC Press), 137-234. doi: 10.1201/EBK1574444865-c5

Ralph, J., Lundquist, K., Brunow, G., Lu, F., Kim, H., Schatz, P. F., et al. (2004). Lignins: natural polymers from oxidative coupling of 4-hydroxyphenylpropanoids. Phytochem. Rev. 3, 29-60. doi: 10.1023/b:phyt.0000047809.65 444.a4
Renders, T., Van den Bosch, S., Koelewijn, S., Schutyser, W., and Sels, B. (2017). Lignin-first biomass fractionation: the advent of active stabilisation strategies. Energy Environ. Sci. Ees 10, 1551-1557. doi: 10.1039/C7EE01298E

Renders, T., Van den Bossche, G., Vangeel, T., Van Aelst, K., and Sels, B. (2019). Reductive catalytic fractionation: state of the art of the lignin-first biorefinery. Curr. Opin. Biotechnol. 56, 193-201. doi: 10.1016/j.copbio.2018.12.005

Rinaldi, R., Jastrzebski, R., Clough, M. T., Ralph, J., Kennema, M., Bruijnincx, P. C., et al. (2016). Paving the way for lignin valorisation: recent advances in bioengineering. Biorefining and Catalysis. Angew. Chem. Int. Ed. Engl. 55, 8164-8215. doi: 10.1002/anie.201510351

Schutyser, W., Renders, T., Van den Bosch, S., Koelewijn, S. F., Beckham, G. T., and Sels, B. F. (2018). Chemicals from lignin: an interplay of lignocellulose fractionation, depolymerisation, and upgrading. Chem. Soc. Rev. 47, 852-908. doi: $10.1039 / \mathrm{c} 7 \mathrm{cs} 00566 \mathrm{k}$

Shu, Z.-F. (1998). The Lightest Tree-Balsa (in chinese). Yunnan: Yunnan Forestry. Shuai, L., Amiri, M. T., Questell-Santiago, Y. M., Héroguel, F., Li, Y., Kim, H., et al. (2016). Formaldehyde stabilization facilitates lignin monomer production during biomass depolymerization. Science 354, 329-333. doi: 10.1126/science. aaf7810

Sluiter, A., Hames, B., Ruiz, R., Scarlata, C., Sluiter, J., Templeton, D., et al. (2008). Determination of structural carbohydrates and lignin in biomass. Lab. Anal. Procedure 1617, 1-16.

Stewart, J. J., Akiyama, T., Chapple, C., Ralph, J., and Mansfield, S. D. (2009). The effects on lignin structure of overexpression of ferulate 5-hydroxylase in hybrid poplar. Plant Physiol. 150, 621-635. doi: 10.1104/pp.109.137059

Wang, H.-M., Ma, C.-Y., Li, H.-Y., Chen, T.-Y., Wen, J.-L., Cao, X.-F., et al. (2020). Structural variations of lignin macromolecules from early growth stages of poplar cell walls. ACS Sustain. Chem. Eng. 8, 1813-1822. doi: 10.1021/ acssuschemeng.9b05845

Wang, H.-M., Wang, B., Wen, J.-L., Yuan, T.-Q., and Sun, R.-C. (2017). Structural characteristics of lignin macromolecules from different eucalyptus species. ACS Sustain. Chem. Eng. 5, 11618-11627. doi: 10.1021/acssuschemeng.7b 02970

Wen, J.-L., Sun, S.-L., Xue, B.-L., and Sun, R.-C. (2013a). Quantitative structural characterization of the lignins from the stem and pith of bamboo (Phyllostachys pubescens). Holzforschung 67, 613-627. doi: 10.1515/hf-20120162

Wen, J.-L., Sun, S.-L., Xue, B.-L., and Sun, R.-C. (2013b). Recent advances in characterization of lignin polymer by solution-state nuclear magnetic resonance (NMR) methodology. Materials 6, 359-391. doi: 10.3390/ma6010359

Wu, S.-B., and Argyropoulos, D. (2003). An improved method for lsolating lignin in high yield and purity. J. Pulp Paper Sci. 29, 235-240. doi: 10.1023/A: 1025117327970

Yuan, T.-Q., Sun, S.-N., Xu, F., and Sun, R.-C. (2011). Characterization of lignin structures and lignin-carbohydrate complex (LCC) linkages by quantitative 13C and 2D HSQC NMR spectroscopy. J. Agricult. Food Chem. 59, 10604-10614. doi: 10.1021/jf2031549

Yuan, T.-Q., Xu, F., He, J., and Sun, R.-C. (2013). Role of lignin in a biorefinery: separation characterization and valorization. J. Chem. Technol. Biotechnol. 88, 346-352. doi: 10.1002/jctb.3996

Zeng, Y.-N., Zhao, S., Yang, S.-H., and Ding, S.-Y. (2014). Lignin plays a negative role in the biochemical process for producing lignocellulosic biofuels. Curr. Opin. Biotechnol. 27, 38-45. doi: 10.1016/j.copbio.2013.09.008

Zhang, A.-P., Lu, F.-C., Sun, R.-C., and Ralph, J. (2010). Isolation of cellulolytic enzyme lignin from wood preswollen/dissolved in dimethyl sulfoxide/Nmethylimidazole. J. Agric. Food Chem. 58, 3446-3450. doi: 10.1021/jf903998d

Conflict of Interest: The authors declare that the research was conducted in the absence of any commercial or financial relationships that could be construed as a potential conflict of interest.

Copyright $\odot 2020$ Zhang, Xu, Ma, Wang, Zhao, Wu and Wen. This is an open-access article distributed under the terms of the Creative Commons Attribution License (CC BY). The use, distribution or reproduction in other forums is permitted, provided the original author(s) and the copyright owner(s) are credited and that the original publication in this journal is cited, in accordance with accepted academic practice. No use, distribution or reproduction is permitted which does not comply with these terms. 